\title{
EDITORIAL
Subdural hematoma in the older population
}

\author{
Perry A. Ball, MD
}

Department of Neurosurgery, Dartmouth-Hitchcock Medical Center, Lebanon, New Hampshire

$\mathrm{T}$ HE study by Won et al. highlights an important problem: With the increase in life expectancy of the population, there are more patients with acute subdural hematoma who are older. ${ }^{2}$ These authors look specifically at patients 80 years of age or older, and, not surprisingly, such patients often have numerous and significant medical comorbidities. Moreover, $75 \%$ of the patients in their study were taking anticoagulation agents at the time of admission. The authors have shown that at 3 months' follow-up, $36 \%$ of patients had a favorable outcome, suggesting that in many cases surgical intervention is worthwhile and beneficial to patients in this age group. The number of comorbidities impacts survival, so there is a place for patient selection and discussions with families on the goals of treatment.

The most striking finding of their study is the marked increase in mortality in the 3 months following hospital discharge. Similar findings have been seen in elderly patients sustaining hip fracture. ${ }^{1}$ It is unclear if this increase in mortality is attributable to the effect of the injury or to the underlying medical conditions. The important question that this finding raises is whether comprehensive medical care in the postdischarge period can impact this mortality. https://thejns.org/doi/abs/10.3171/2017.8.FOCUS17529

\section{References}

1. Haentjens P, Magaziner J, Colón-Emeric S, Vanderschueren D, Millisen K, Velkeniers B, et al: Meta-analysis: excess mortality after hip fracture among older women and men. Ann Int Med 152:380-390, 2010

2. Won SY, Dubinski D, Brawanski N, Strzelcyk A, Seifert V, Freiman TM, et al: Significant increase in acute subdual hematoma in octo- and nonagenarians: surgical treatment, functional outcome, and predictors in this patient cohort. Neurosurg Focus 43(5):E10, 2017

\section{Disclosures}

The author reports no conflict of interest. 